Instructions for authors, subscriptions and further details:

http://brac.hipatiapress.com

\title{
Picasso, Alta y Baja Cultura a Final de Siglo Inocente Soto ${ }^{1}$
}

1) Universidad de Málaga

Date of publication: June $3^{\text {rd }}, 2019$

Edition period: February 2019 - June 2019

To cite this article: Soto, I. (2019). Picasso, Alta y Baja Cultura a Final de Siglo. Barcelona, Research, Art, Creation, 7(2) 114-136. doi:

10.17583/brac.2019.2677

To link this article: http://dx.doi.org/10.17583/brac.2019.2677

\section{PLEASE SCROLL DOWN FOR ARTICLE}

The terms and conditions of use are related to the Open Journal System and to Creative Commons Attribution License (CC-BY). 
BRAC - Barcelona Research Art Creation. Vol. 7 No. 2, June 2019, pp. 114-136

\section{Picasso, High and Low Culture at the End of the Century}

Inocente Soto Calzado

Universidad de Málaga

(Received: 2 April 2017; Accepted: 8 April 2019; Published: 3 June 2019)

\section{Abstract}

The look of the popular culture to art has always had for the creator the contrariety of the mockery and the reward of the diffusion, to make itself known in the new media of masses multiplying its public, halfway between the admiration and the ridiculous. Painters and sculptors checked it for the first time at the end of the 19th century, between official and specialized criticism and the most popular and apparently less objective of comedians and their humorous interpretations. One of these artists was the young Pablo Ruiz Picasso, with some unknown graphic criticism that give new information on the complexity of his first Spanish artistic stage and the importance of illustrated magazines in the visual culture of his beginnings and in his professional world. The data collected in the hemerography of the time make up a narrative different from the one officially admitted.

Keywords: Picasso, high and low culture, illustration, magazines, exhibition 
BRAC - Barcelona Research Art Creation. Vol. 7 No. 2, June 2019, pp. 114-136

\section{Picasso, Alta y Baja Cultura a Final de Siglo}

Inocente Soto Calzado

Universidad de Málaga

(Recibido: 4 abril 2017; Aceptado: 8 junio 2019; Publicado: 3 junio 2019)

\section{Resumen}

La mirada de la cultura popular hacia el arte siempre ha tenido para el creador la contrariedad de la burla y la recompensa de la difusión, darse a conocer en los nuevos medios de comunicación de masas multiplicando su público, a medias entre la admiración y el ridículo. Lo comprobaron por primera vez pintores y escultores al final del siglo XIX, entre la crítica oficial y especializada y la más popular y en apariencia menos objetiva de humoristas y sus jocosas interpretaciones. Uno de esos artistas era el joven Pablo Ruiz Picasso, con algunas críticas gráficas desconocidas que arrojan nuevos datos sobre la complejidad de su primera etapa artística española y la importancia de las revistas ilustradas en la cultura visual de sus inicios y en su mundo profesional. Los datos recogidos en la hemerografía de la época componen una narración distinta de la oficialmente admitida.

Palabras clave: Picasso, alta y baja cultura, ilustración, revistas, exposición 


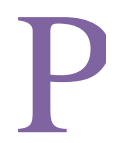

ablo Ruiz Picasso (1881-1973) puso todo su empeño desde la adolescencia para desarrollar sus capacidades artísticas y vivir de ello, dirigido sin duda desde un primer momento por su propio padre José Ruiz Blasco, a su vez pintor y profesor de arte (Ocaña, 2003, pp. 17-32). Picasso había comenzado sus estudios de Bellas Artes con diez años y realizado sus primeras exposiciones en A Coruña, ya con trece años de edad, recibiendo buenas, aunque escuetas críticas en los principales periódicos locales (Pardo; Ventureira, 2014, pp. 230, 239, 257). A pesar de esas positivas informaciones locales, en medio de una pléyade de excelentes pintores jóvenes a veces de mayor precocidad, las posibilidades de destacar del joven aspirante dentro de un mundo altamente competitivo a nivel nacional eran mínimas.

Conseguir fama en las exposiciones locales, regionales o nacionales, la docencia en estudios oficiales o academias particulares, los trabajos decorativos y la participación en ilustraciones de revistas y libros eran formas de subsistencia para los aspirantes a artistas profesionales, a menudo llevadas a cabo en paralelo (García Guatas, 2013, pp. 314-315, 318). José Ruiz Blasco guiará la carrera de su hijo siguiendo sus frustradas aspiraciones, deseando para él los éxitos que como artista o profesor no había podido obtener, recordando que la falta de galardones en las exposiciones nacionales impidió su propia promoción en la carrera docente, conduciéndolo al abandono de su ciudad natal y al traslado de toda su familia a diferentes ciudades (Pazos, 1981, p. 14). La importancia de esas exposiciones nacionales de Bellas Artes, desde su creación a mitad del siglo XIX hasta su lenta agonía en el siglo XX, ha sido analizada en diversas ocasiones, coincidiendo en otorgarle el papel en sus inicios de motor de desarrollo del arte español (Caparrós, 2014, p. 15).

Picasso inicia el camino de los certámenes pictóricos a muy temprana edad, en 1895, antes de cumplir catorce años, en el Certamen del Liceo de Málaga, una institución al servicio de la clase alta de la ciudad. Con el cuadro Viejo (Palomo, 1985, p. 192) obtiene una tercera medalla de bronce justo antes de su partida para su nueva ciudad, Barcelona, donde su padre ocupará, mediante permuta, una plaza en la Escuela de Arte. Desde entonces continuará casi ininterrumpidamente presentándose a esos concursos oficiales durante seis años, tanto en Málaga como en Barcelona, Madrid y París, hasta 1901, con poca atención de la crítica oficial y alguna más del periodismo cómico. 


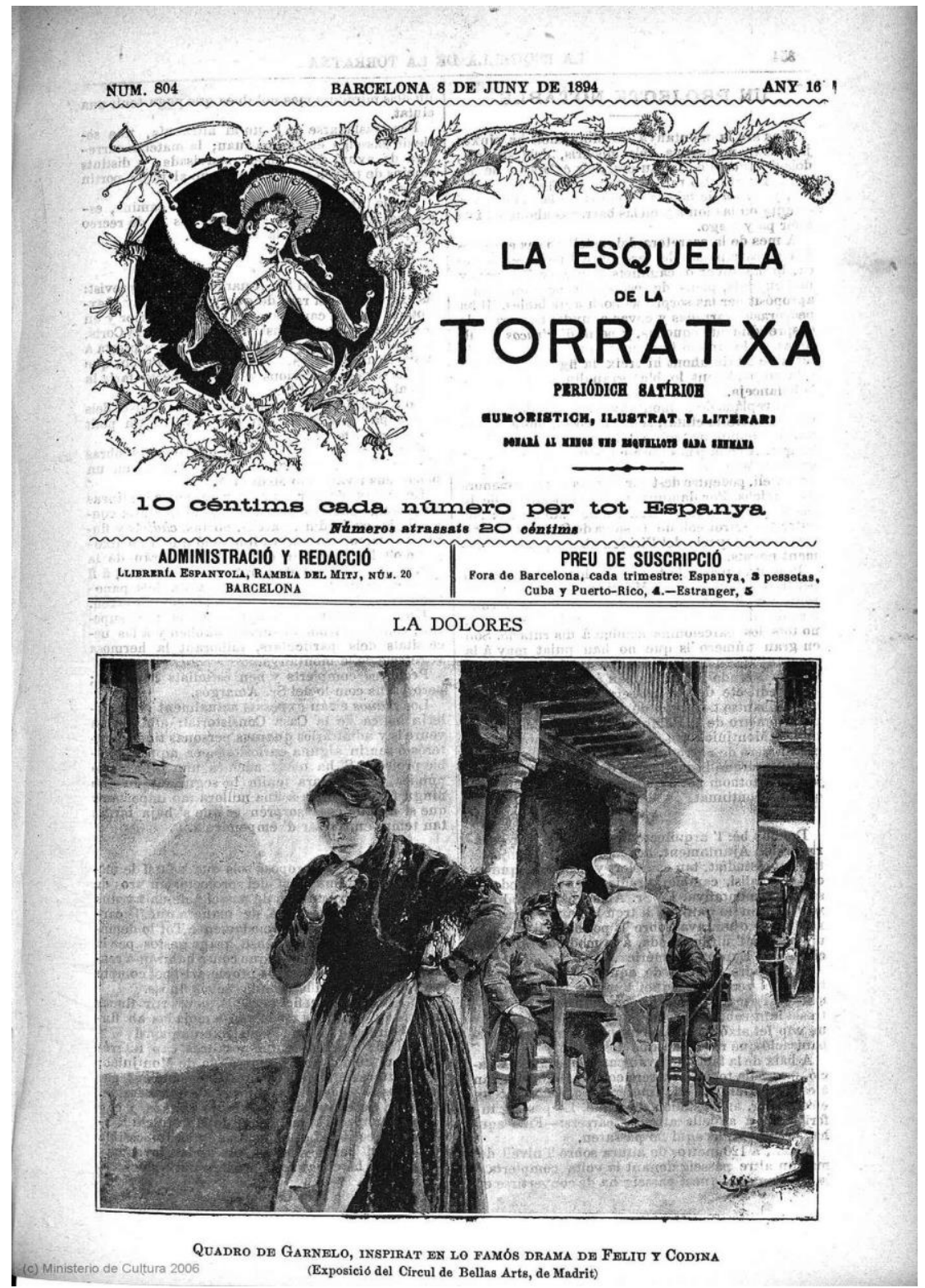

Imagen 1. Garnelo Alda, J. (1894). La Dolores. Cuadro en paradero desconocido. Fotograbado en La Esquella de la Torratxa, año 16, 8/6/1894, no 804, portada. Col. BASL, Málaga. 
No suele pararse mucho la literatura picassiana en los primeros años de creación, con pocos datos que permitan la exaltación hagiográfica, y cuando lo hace el análisis del entorno y la cultura de la época suele ser superficial. En 1896, en su nueva ciudad, Barcelona, donde todavía no ha cumplido el año de residencia, el joven artista concurre a la III Exposición de Bellas Artes e Industrias Artísticas con Primera Comunión. Las exposiciones municipales habían nacido en la ciudad mostrando la pujanza de ese período de revitalización económica y cultural conocido como Renaixença, buscando la creación de una colección artística para los futuros museos y el apoyo explícito a los artistas (Ojuel, 2013, p. 97). Picasso va a concursar con un cuadro al efecto, tanto por sus medidas (166 x $118 \mathrm{~cm}$.) como por su temática costumbrista. José Garnelo Alda, reputado artista y profesor de la Escuela de Artes de Barcelona, que había cosechado un gran éxito a comienzos del año en su exposición del salón Parés barcelonés (Ossorio, 1896, p.151), prestó su taller para que el joven trabajara la composición y dio seguramente más de un consejo. José Garnelo, compañero de trabajo del padre de Picasso, con su hermano Manuel Garnelo compartiendo aula con el propio Picasso, era con 30 años todo lo que José Ruiz querría que pudiera llegar a ser su hijo: profesor de arte, anteriormente pensionado en la Academia de España en Roma y con dos segundas y una primera medalla en las exposiciones nacionales de Bellas Artes (Clémentson, 1985, pp. 38-41); antes de su traslado a la ciudad condal su obra había aparecido en algunas de las revistas barcelonesas más leídas, dirigidas a un público muy diverso, entre las que se contaban La Ilustración Artística, Barcelona Cómica o La Esquella de la Torratxa (véase Imagen 1). Entre sus éxitos Garnelo había simultaneado la temática histórica con la contemporánea, salpimentando esta última con buenas dosis de dramatismo. Compositiva y temáticamente el cuadro de Picasso está muy próximo a la disposición que Garnelo realizó para su obra Flores a la Virgen, expuesta en el salón Parés a principios de 1896 y reproducida en prensa, con la presencia del altar, la niña con el progenitor y una figura secundaria femenina. El cuadro de Picasso hubo de competir con otros de similar ambiente, que aprovechaban de una u otra forma el recogimiento y trascendentalidad del interior de una iglesia, como los de Anselmo Guinea y Mas i Fontdevila, y a pesar de no obtener ningún premio, llamó la atención de Manuel Moliné, sexagenario trabajador de la imagen, fotógrafo y caricaturista (Casado, 2006, pp. 120-122), uno de los dibujantes fijos en la redacción de La Esquella de la Torratxa. Con ello conquistó el dudoso honor de aparecer en una de las parodias de la Exposición con el siguiente pie de corte jocoso y no poca gracia: "Pare tan 
cuydadós de sa filla, que se li posa al costat de centinella mentres aquesta fá la primera comunió" ("Padre tan pendiente de su hija que le pone un centinela mientras hace la primera comunión"). Para que no hubiera duda, trabajando la metáfora visual, el dibujante había cambiado el traje festivo por un uniforme militar capa incluida y mosquetón con bayoneta calada en vertical; don José bien podría ser ese padre centinela en la comunión de Picasso con la pintura oficialista. Moliné pretende ser respetuoso con la composición del joven Picasso, pero solo en apariencia, pues lo primero que hace es una maliciosa selección copiando el bloque de la izquierda con los tres personajes, cada uno con un espacio muy concreto en el cuadro, circunstancia a la que se le saca partido en el texto cómico poniendo en tela de juicio la relación entre las figuras; condena al olvido a la mayor parte derecha del cuadro, donde se desarrolla una escena secundaria con el monaguillo junto al altar con naturaleza muerta de candelabro y floreros, simplificando la complejidad de la estructura escenográfica pero creando una relación visual entre los jovencitos inexistente en el original, dando razones de peso a la vigilancia paterna (véase Imagen 2). La ordenación espacial de Picasso, que todavía no había cumplido quince años, su control de las zonas de mayor luminosidad, dándole la importancia debida a las distintas figuras con una solvencia absoluta, ha sido manipulada para crear una escena aparentemente igual pero totalmente distinta: la mirada de Moliné sustituye santidad por paganismo con habilidad y una técnica sencilla pero efectiva, adaptada al medio reproductivo del fotograbado de línea, plena de convencionalismos como los tramados lineales que crean distintas zonas de sombra y de penumbra, desmontando el andamiaje compositivo hasta prescindir incluso de la perspectiva cónica del cuadro original y del punto de fuga que ayudaba a centrar el discurso sobre la figura de la inmaculada niña. La base del trabajo humorístico es la dicotomía forma-contenido, un ligero pero contundente juicio sobre la coherencia entre plástica y estética. Dos años más tarde Picasso sería compañero ocasional de Moliné en la publicación anual Almanach de La Esquella de la Torratxa.

Los apuntes cómicos a los que quedaban expuestos sus cuadros de exposición pueden tener una lectura negativa (Rojas, 1981, p. 93), pero tampoco se puede perder de vista que era un uso de la época sufrido por noveles y consagrados, no un ensañamiento, y le permitía al joven Pablo unirse en las páginas de las revistas con otros artistas ya consagrados, igual de expuestos que él al chiste fácil, a veces amable y otras cruel, afortunado y no tanto, tal y como compartía burlas en la página de Moliné de 1896 con una parodia de un cuadro de Eliseu Meifrén y una escultura de Eusebi 
Arnau. Para un debutante como él era toda una suerte llamar de esa manera la atención del lector, futuro espectador (Esain, 1992, p. 54), cuando el ilustrador traducía humorísticamente el cuadro a un público mayoritario para el que la estética y los valores de la Pintura al uso no formaban parte de su cotidianeidad. El gran arte auspiciado por la crítica iba dirigido al público que podía pagarlo, minoritario, perteneciente a la clase alta, una mezcla de aristocracia y burguesía con un gusto muy determinado basculante entre el historicismo oficial y el costumbrismo popular, poco proclive a innovaciones fuera del guión (Sureda; Guasch, 1993, p. 12). El chiste pictórico era un síntoma del acceso al arte de una nueva clase de espectador, que posiblemente nunca sería propietario de ninguna obra pero que adquiría, con el precio de la entrada de la Exposición, el derecho a hablar sobre las imágenes que se le ofrecían, en connivencia con el humorista gráfico.

Las caricaturas sobre la obra de Picasso hablan sobre su etapa primeriza y la facilidad de las transformaciones gráficas, y explican al mismo tiempo algún misterio de su cronología. Hay un gran vacío expositivo en la biografía de Picasso en 1898, extraña, pues desde 1895 es continua su presencia en distintos certámenes, como los mencionados de Málaga de 1895 y Barcelona de 1896, la Exposición Nacional de Madrid de 1897 donde consigue mención honorífica y las posteriores en 1899 de Madrid (otra mención) y Málaga, la Exposición Internacional de París en 1900, tras realizar su primera exposición individual en Els Quatre Gats, y la Exposición Nacional de Bellas Artes de Madrid por última vez en 1901. No parece normal, en esa línea regular y continua de presencias en concursos oficiales y muestras, la discontinuidad en 1898, sin aparecer en ningún certamen, aunque tampoco se le ha dado mucha importancia, ya que el año fue especialmente complicado para el joven, que había empezado en 1897 el curso en Madrid y terminó antes de tiempo su estancia académica en la capital de España, volviendo a Barcelona. El único dato hasta el momento sobre la participación de Picasso en una exposición de ese año se encuentra precisamente en forma de crítica gráfica, entre las páginas de una revista.

Cuando se inaugura en el mes de abril de 1898 la IV Exposición de Bellas Artes e Industrias Artísticas de Barcelona, Picasso está en Madrid, ciudad donde ha iniciado estudios de Bellas Artes el año anterior y que abandonará aquejado de una enfermedad de cierta gravedad para volver a Barcelona -en pleno desarrollo de la exposición- y marchar poco después al pueblo de Horta de Sant Joan para pasar una temporada junto a su amigo Manuel Pallarés. Se discute la fecha de su llegada a Barcelona (Richardson, 1995, p. 97), aunque la propia obra de Picasso ayuda a situarse en el tiempo, 
existiendo un dibujo con la inscripción "6-30 tarde 21 de mayo de 1898 (en Madrid)” (Barrachina et al., 1986, MPB 111.480) y otro con la leyenda "Barcelona-junio-1898" (Zervos, 1969, il. 75). Ninguna de las más acreditadas biografías habla sobre la posibilidad de que el malagueño hubiera participado en esa Exposición de Barcelona de 1898; a lo sumo, se especula tímidamente que habría podido formar parte del público: "No sabemos si, durante aquellas jornadas en Barcelona, Picasso visitó la Exposición General de Bellas Artes de 1898, que aún seguía abierta. Es posible que, en esta ocasión, su paso por la Ciudad Condal fuera más bien tangencial" (Palau, 1980, p. 142). El lápiz de un sarcástico dibujante parece demostrar lo contrario.

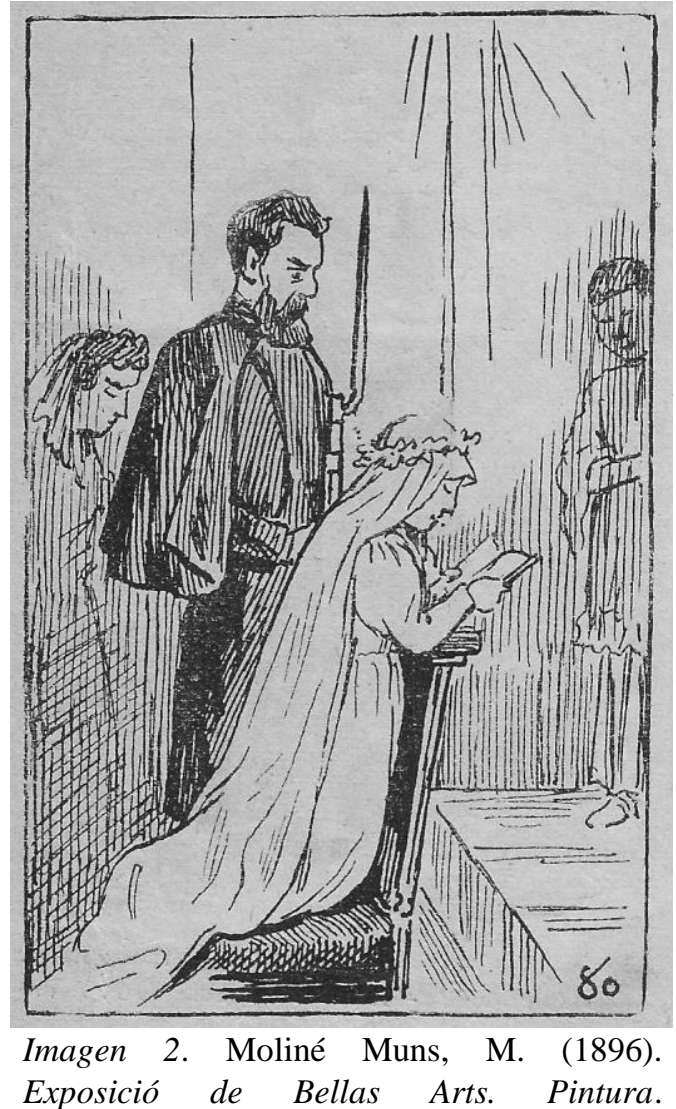

Fotograbado en La Esquella de la Torratxa, Barcelona, no 909, 12/6/1896, p. 382. Col. BASL, Málaga. 
La IV Exposición de Bellas Artes e Industrias Artísticas de Barcelona empezó a gestarse administrativamente a finales de 1897, con la publicación en el mes de noviembre de su Reglamento, donde se disponía que el plazo para la presentación de obras sería desde el día 15 al 30 de marzo de 1898 en el Palacio de Bellas Artes; si las obras de provincias y del extranjero hubieran sido expedidas en su punto de origen dentro del plazo, se aceptarían a pesar de su retardo, siempre por causas imprevistas y justificadas (Reglamento Cuarta Exposición de Bellas Artes e Industrias Artísticas, Ayuntamiento, Barcelona, 1898). Ciertamente, el hecho de que haya unos 20 días entre el último día de presentación y la instalación de obras (donde se colocaron unas 1800 en total y más de 700 cuadros) parece un tiempo escaso. A fines de enero de 1898 se anunciaron las bases del concurso público para la edición del catálogo ilustrado, que debía estar terminado veinte días después de entregado el material y designadas las obras que debían figurar en la sección ilustrada, y a finales de febrero se sabía que la empresa Henrich y Cía había ganado dicho concurso ( $L a$ Vanguardia, 29/1/1898, p. 3 y 26/2/1898, p. 2, respectivamente). La muestra comenzó el 22 de abril con el Acto de barnizado y Terminación de la Instalación de obras, con acceso por invitación (Arxiu Històric de la Ciutat de Barcelona, Barcelona, AHCB4-326/C14.02, PBA-10). En ese tradicional vernissage los invitados pudieron ver la sección de Pintura totalmente montada y lista, como puede observarse en una de las ilustraciones publicada algo tardíamente, un dibujo del natural que intenta recoger fielmente el ambiente de las salas y la disposición de los lienzos a distintos niveles sobre la pared, observados por un heterogéneo público de ancianos, señores, señoras y alguna niña (La Ilustración Ibérica, nº 802, 14/5/1898, p. 311). Al día siguiente ya estaba abierta la muestra a los demás espectadores.

A pesar de coincidir con la guerra hispano-estadounidense, y no sin críticas por el hecho de celebrar un banquete de inauguración mientras el país perdía a sus héroes (La Esquella de la Torratxa, año 20, n 1007, 29/4/1898, p. 283), las revistas barcelonesas -entre las que cabe citar Álbum Salón o La Ilustración Artística- y alguna que otra editada desde Madrid La Ilustración Española y Americana- procuraron recoger el evento. Se editó el catálogo, ilustrado con 73 reproducciones y citando en sus 302 páginas las 1.804 obras participantes en las distintas categorías (Catálogo ilustrado. IV Exposición de Bellas Artes e Industrias Artísticas 1898, Henrich y Cía en comandita, Barcelona, 1898). El jurado de recompensas se reunió durante el mes de mayo y su fallo fue hecho público al final de dicho mes; el 10 de julio se clausuraba la exposición, y ello significaba que la 
retirada de las obras se debía de producir en un plazo de quince días ( $L a$ Vanguardia, 22/5/1898, p. 4 y 11/7/1898, p. 1, respectivamente). Su duración no había alcanzado los tres meses, pero sus números se daban por correctos, cifrándose la asistencia en una media de más de 400 personas diarias, similar al certamen de la Feria Concurso Agrícola con la que había coincidido en la ciudad y en el tiempo (La Dinastía, n $^{\circ} 6550,26 / 5 / 1898$ ). La VI Exposición Bienal del Círculo de Bellas Artes de Madrid se celebró en paralelo, pudiendo haberle restado la participación de algunos autores.

Era el momento en que la población, saturada por ilustraciones bélicas cuya menor o mayor bondad estética no podía ocultar la realidad, necesitaba otros temas, otras formas y una visión más amable sobre la cotidianeidad. $E l$ Gato Negro, publicación ilustrada fundada y dirigida por Carlos Ossorio (Sánchez Vigil, 2008, p. 124), se ocupa de la IV Exposición de Bellas Artes e Industrias Artísticas de Barcelona en sus números 18 al 20, comenzando el 14 de mayo y terminando el 28 del mismo mes. La revista era un proyecto de grandes aspiraciones, que anunció un extenso plantel de colaboradores de lo más granado, pero sus páginas sirvieron sobre todo para el debut de jóvenes promesas no contempladas en el plan primitivo, como fueron Joan Cardona Lladós y Xavier Gosé.

La cultura de masas se nutre de la cultura elitista, de la cual proviene, con modelos de la clase dominante construidos a partir del código de dicha élite (Eco, 1995, p. 42). La sociedad, la mayoría, necesita compartir y al mismo tiempo subvertir dichos códigos de minorías. La noticia de la participación de Picasso en la Exposición de Barcelona viene dada por el ingenio de Joaquim Xaudaró, prolífico y ya famoso. Con una marcada inclinación hacia las Bellas Artes, su biografía fija hasta 1890 su práctica de la pintura del natural para concentrarse después en el dibujo de caricaturas (Casado, 2006, p. 215); sin embargo, testimonios coetáneos lo hacen estudiante de Bellas Artes bajo las órdenes de Díaz y Antonio Caba y condiscípulo de Ricard Urgell y Joaquim Mir (Sanmartín, 1901, s.p.), por lo tanto debió estudiar en la Lonja, la Academia de Bellas Artes de Barcelona, por lo menos durante el curso 1894-1895, cuando Mir estuvo allí (Jardí, 1975, p. 12); hay que recordar que Ricard Urgell fue compañero de Picasso en el curso 1896-1897, y colaboró en 1897 en la revista The Monigoty codirigida por Xaudaró. El dibujante Xaudaró, una vez abandonada la pintura, comenzó su carrera colaborando en Barcelona Cómica y a continuación en una gran variedad de revistas ilustradas, tanto en Barcelona como en Madrid; en 1898, además de empezar a publicar su obra en álbumes monográficos, se le podía encontrar en La Hormiga de Oro, Álbum Salón, La Lectura Dominical, Madrid 
Cómico o Blanco y Negro, reencontrándose con Ossorio, anterior director de Barcelona Cómica, en El Gato Negro.

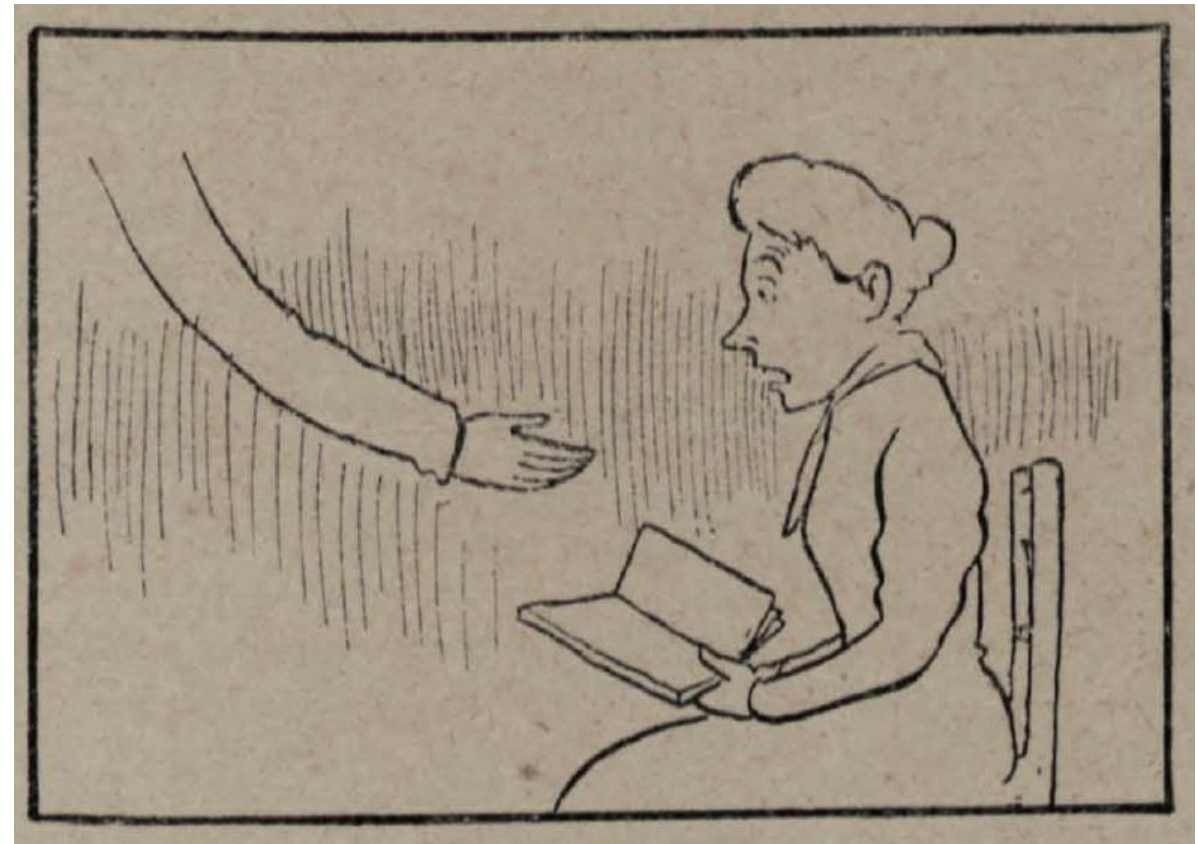

Imagen 3. Xaudaró Echau, J. (1898). Exposición de Bellas Artes. Fotograbado en El Gato Negro, Barcelona, tomo I, nº 18, 14/5/1898, s/p. Col. BASL, Málaga.

En el número 18 de El Gato Negro, tomo I, con fecha 14 de mayo de 1898, aparece una sección titulada Exposición de Bellas Artes de Barcelona, por Xaudaró, consistente en dos viñetas representando dos cuadros de dicha exposición en versión humorística. La primera de ellas, con el pie "P. Ruiz. -iUna aparición!"', representa un brazo con mano abierta que surge de la nada desde la izquierda y que se dirige a una mujer sentada a la derecha con un libro abierto en las suyas, sorprendida y asustada; unas líneas verticales tras las dos figuras sugieren que la escena se desarrolla en un espacio en penumbra, sin fondo definido (véase Imagen 3). La firma P. Ruiz, típica de Picasso en la época, es imposible encontrarla en el catálogo oficial. Xaudaró tuvo que ver ese cuadro en la Exposición, y a partir de un sencillo apunte lo trasformó en burla visual, una chanza que presupone y necesita, sobre todo, del conocimiento del espectador del original para que se produzca el mayor efecto cómico. El propio Xaudaró pudo ignorar que $P$. Ruiz no aparecía en 
el catálogo oficial, pues este salió a la luz pública más tarde. Dilucidar porqué Picasso no aparece en el catálogo oficial si estuvo presente en la muestra requiere nuevas explicaciones, siempre pensando que el cuadro debía haber sido enviado desde Madrid, contemplando el hecho de que el envío llegara tarde o fuera de plazo, por un problema de transporte previsto en el Reglamento o no justificado, subsanado irregularmente, como parece ser ocurrió en otros casos por la buena voluntad del Jurado o la presión sobre él (Ojuel, 2013, p. 259), para lo cual no hay que olvidar que José Garnelo Alda, compañero de José Ruiz Blasco en la Escuela Provincial de Bellas Artes de Barcelona y en cuyo estudio Picasso preparó el cuadro presentado al certamen de 1896, era vocal de dicho Jurado en concepto de artista, tal y como se recoge en el catálogo.

Siendo Picasso un autor cuya obra está ampliamente catalogada y cuyo método de trabajo insiste en variaciones sobre un tema, una hipótesis sobre el cuadro expuesto, punto de partida de la metamorfosis ejecutada por Xaudaró, debe contemplar la existencia de obras del joven Pablo con el modelo de mujer sedente leyendo o posando en un interior, las cuales se dan desde fecha temprana, ligadas a la idea del bosquejo rápido. Tras repasar las creaciones del malagueño en años anteriores y posteriores (Mallén, 2017) las más cercanas están datadas hacia 1899 y son de formato vertical, a diferencia de la parodia de Xaudaró, el cual bien es cierto basa toda la ilustración exclusivamente en la anécdota de la relación mano-cara. Hay varios dibujos donde la figura siempre se muestra a la izquierda de la composición y no existe nada que pudiera sugerir el motivo de la mano (Barrachina et al, 1986, MPB 110.230 y 110.238); otro grupo que corresponde al mismo modelo, donde el atavío femenino se sofistica y la mujer se rejuvenece, da la clave de la re-creación de Xaudaró: muestran la figura a la derecha, junto a una ventana, y en ella se vislumbran los resplandores del exterior, en unos fuertes tonos anaranjados de masa informe, tras los cristales. Así ocurre en una obra de pequeñas dimensiones, actualmente en el museo de Arte de Cleveland, Lola, la hermana del artista, presentando ese ventanal a la izquierda de la joven Lola con clavel y mantilla (Zervos, 1969, n 80); con más coincidencias en la figura femenina destaca Lola delante de una ventana (véase Imagen 4), fechada tradicionalmente entre febrero y marzo de 1899, tras la vuelta de Picasso de Horta de Sant Joan, uniendo las formas de los cálidos reflejos en los vidrios con un fondo oscuro, pudiendo haber inspirado su estructura la idea de un brazo avanzando hacia la mujer ensimismada. Es posible que no fuera exactamente el cuadro visto por Xaudaró, pero no debiera ser muy distinto. 
La obra perteneció durante toda su vida a Picasso, acompañándolo por sus diversos talleres, y a su fallecimiento pasó a la colección de su nieta Marina (Carandente, 1981, p. 156)

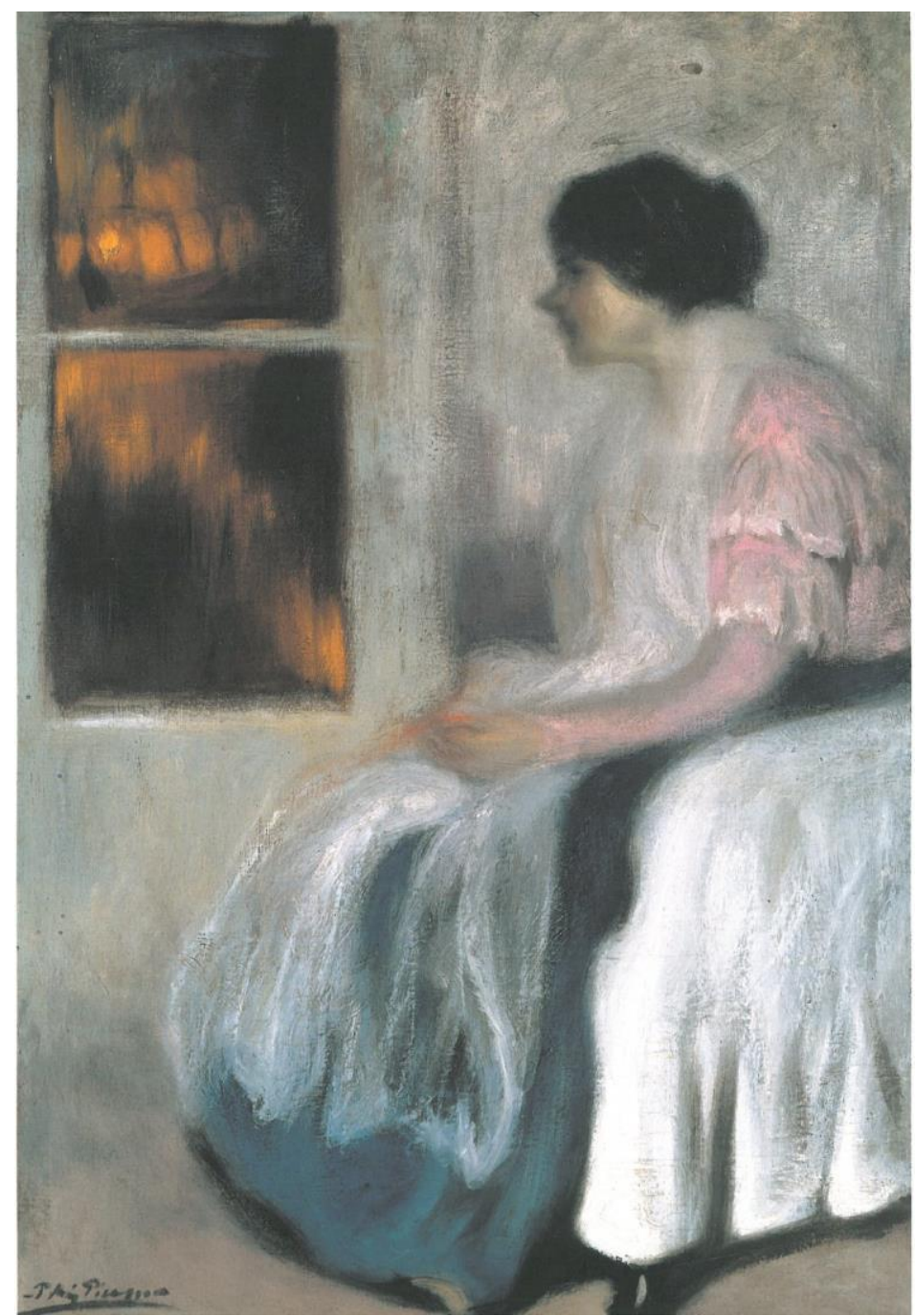

Imagen 4. Ruiz Picasso, P. (1899, datación). Lola delante de una ventana. Óleo sobre tela. 151 x $100 \mathrm{~cm}$. Colección Marina Picasso. Reimpreso de Giovanni Carandente (p. 87), Picasso. Opere dal 1895 al 1971 dalla collezione Marina Picasso, Sansoni, 1981, Florencia. Agradecimientos al Centro de Documentación de la Fundación Picasso de Málaga. 
Este cuadro, pintado en un formato con unas medidas muy cercanas a las de su anterior participación con Primera Comunión, es clave para la comprensión de su evolución, porque supone una ruptura total con la pintura realizada con anterioridad en gran formato y para certamen, como una reivindicación de una manera propia de entender el arte ya lejana del esquema paternal, acorde con la crisis artística vivida en su estancia madrileña. Lola delante de una ventana señala una posición personal e innovadora, acercándose al ámbito contemporáneo catalán y a su pintura más exitosa, muy cercana en muchos aspectos a la obra del olvidado Lluis Graner, aficionado a las escenas iluminadas artificialmente por la luz del nuevo siglo y a esos tonos encendidos y cálidos, amarillentos y anaranjados, que ya se le reprocharan a sus paisajes (Casellas, 1892, p. 5), característicos del Grupo del Azafrán o Colla del Safrà formado por sus discípulos Mir y Nonell junto a Sunyer, Canals, Gual, Pichot y Vallmitjana. Graner no solo dibujaría en 1899 para El Gato Negro, sino que su obra era actualidad en 1898, presente en exposiciones, así como en postales para la marca de cigarros Job o en portadas de revistas a color, como los números de Álbum Salón de cuidadosa edición a color con papel satinado (véase Imagen 5). Graner, presente también en la VI Exposición Bienal del Círculo de Bellas Artes en Madrid, fue piropeado de esta manera por un periodista: "Ya en la exposición última demostró Graner que pinta la luz artificial como pocos y las sombras de la noche como nadie. Con el cuadro de ahora confirma el anterior triunfo y renueva los aplausos que escuchó entonces" (Rovira, 1898, p. 4).

La broma amable y gentil de Xaudaró en El Gato Negro descubre un nuevo y sugerente Picasso aún más precoz, de ideas avanzadas antes de su paso por Horta de Sant Joan, que utiliza escenas cotidianas, habla del ambiente contemporáneo y urbano y de la intimidad, con formas actuales sobre nuevos temas. Picasso ensayaría su nuevo camino y prorrogaría esa exploración de los tonos anaranjados en el conocido Retrato de Josep Cardona (hombre con lámpara), donde la imagen se sigue construyendo con una pincelada larga y fibrosa típica de la época, con una preocupación en el color y la luminosidad sin olvidar nunca la preponderancia de la forma, ya que no es ajeno al método de trabajo picassiano la recuperación y reelaboración de un modelo anterior; iconográficamente se volvería a acercar a la pintura de Graner dedicada a los retratos de personalidades en interiores, como Retrato del crítico de arte y escritor Raimon Casellas o el posterior Retrato de Joaquim Cabot Rovira, modelos de prestigio y obras de madurez con un sello personal incuestionable, a los que Picasso incorpora 
una amplia gama de matices blanquecinos, suavizando el efectismo tenebrista.

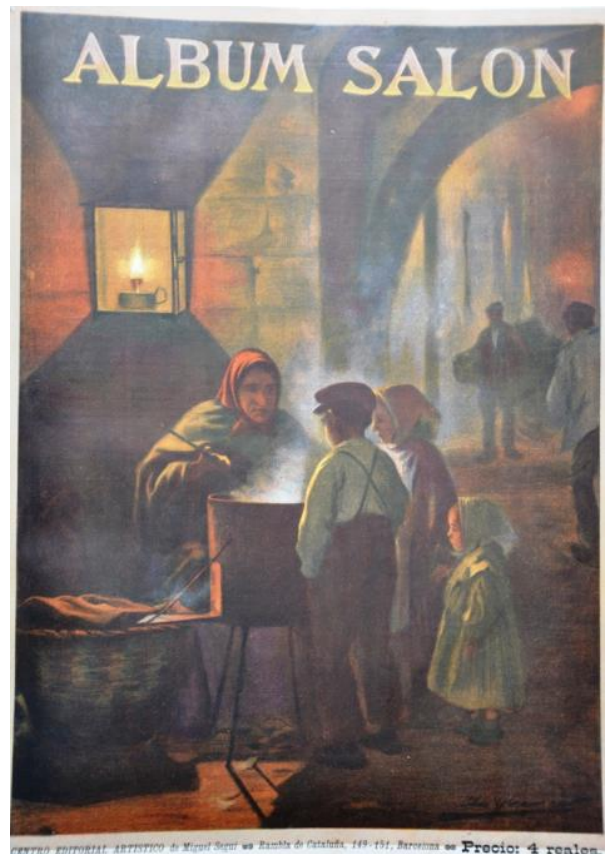

Imagen 5. Graner Arrufí, L. (1898). Fotograbado en Álbum Salón, Barcelona, $\mathrm{n}^{\circ}$ 8, 9/1/1898, portada. Col. BASL, Málaga.

La turbulencia de esos años adolescentes es, como siempre en Picasso, vital y pictórica, con el arte entendido como biografía, y por ello se han situado tanto Lola delante de una ventana como Retrato de Josep Cardona entre el modernismo y el academicismo, en plena búsqueda personal (García-Herraiz, 1997, p. 43). Aunque tradicionalmente se han datado estas obras tras la vuelta de Horta de Sant Joan, se puede interpretar Lola delante de una ventana, tras la revelación propiciada por Xaudaró, como un antecedente, una liberación en su primera etapa madrileña, manifiesto artístico y personal, toma de posición ante las estéticas barcelonesas fin de siglo, asumidas por un joven de 17 años capaz de crear con su mano y con su mirada, a partir del arte más actual a su alrededor y de su elección personal (hay que recordar que Lola se desplazó a Madrid en 1898 para atender al hermano en su enfermedad). Las hipótesis expuestas señalan que la eclosión del creador y su rompimiento con los moldes oficiales es anterior a lo que se 
creía hasta ahora, antes de Horta de Sant Joan y de los señalados dibujos del Cercle Artístic de Sant Lluc analizados como nuevas exploraciones (Staller, 2001, p. 103).

El certamen barcelonés en su cuarta edición era un acontecimiento artístico importante a nivel nacional, internacional e imprescindible para cualquier artista ligado a la ciudad. Si se comparan los nombres del catálogo con los listados de alumnos de los dos años en los que Picasso formó parte de la Escuela de Bellas Artes (Palau, 1980, pp. 204-208) participan en la sección de pintura más de diez compañeros de clase de la Lonja, junto a los conocidos Pallarés, Cardona Lladós, Torné Esquius o Ricard Urgell. Todos los pintores versionados por Xaudaró en los tres números de El Gato Negro (Ernesto Soler de las Casas, Pedro Buxareu, Antonio Aspert, Ramon Casas, José Alea, Carlos Vázquez, Pablo María Bertrán, Joaquim Vancells, Estanislao Torrents y José Sancho), aparecen en el catálogo oficial con sus obras, salvo P. Ruiz. Observar otros ejemplos del sistema de trabajo de Xaudaró puede ayudar a comprender la transformación sobre el cuadro de Picasso. En el número 19 de El Gato Negro, tomo I, con fecha 21 de mayo de 1898, el humorista va a parodiar un lienzo de Ramón Casas, que aparece con el pie "R. Casas. -Rompecabezas chino: ¿Dónde están los muebles y el cuerpo de la nena?", tratándose, de entre sus cuatro óleos presentados, del número 124 Catalinita, expuesto en la Sala Segunda. El conocido cuadro ilustra el proceso: Casas había realizado un retrato de su sobrina Catalina Nieto (Doñate; Mendoza, 2001, p. 184) inmersa en el ambiente de un salón monocromáticamente blanco, pero el exceso armónico es roto, no solo por la cabeza de la retratada (además de manos y piernas con medias y zapatos oscuros) sino, clave compositiva y cromática, por la parte inferior de la puerta, fuerte contraposición de marrón cálido en el ángulo superior izquierdo (véase Imagen 6). Es un cuadro con un contraste muy fuerte, apagado por el gran dominio espacial de las superficies en blanco. Xaudaró capta todo eso, fundiendo mobiliario y fondo en el blanco del papel, olvidando el tono de separación entre el sofá y el suelo, y forzando el contraste al cambiar la indumentaria de la niña, a la que hace abrir los brazos como llamada de atención ante el espacio vacío (véase Imagen 7). En la misma página de la publicación Casas era elogiado por el articulista mientras Zuloaga y Rusiñol sufrían sus frases: "Ha sorteado bien la dificultad de tanta clase de blancos, y la niña resulta muy artística" (Ortiz, 1898, s. p.). Es evidente que Ramon Casas suponía para Picasso un nuevo y moderno modelo de artista, alejado de la propuesta paterna (Fanés, 2012, p. 22), de la misma forma que también correspondía a esa imagen Santiago Rusiñol 
(Vallès, 2010, p. 124). Xaudaró, antiguo pintor y ocupado dibujante, deja su opinión gráfica sobre los nuevos usos pictóricos de los artistas de su ciudad y la nueva pintura.

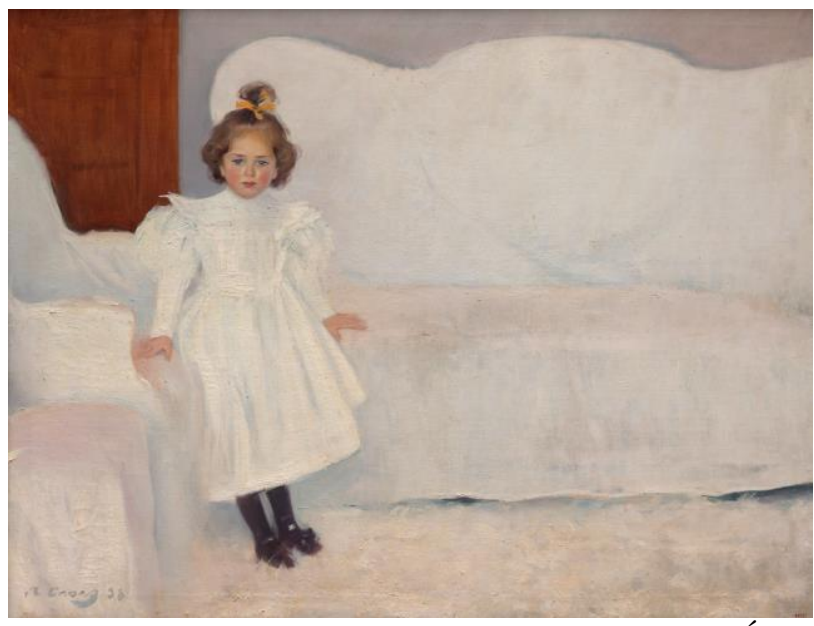

Imagen 6. Casas Carbó, R. (1898). Catalinita. Óleo sobre tela. 1898. 127 x $166 \mathrm{~cm}$. Colección Masaveu. Reimpreso de Mercè Doñate y Cristina Mendoza (p. 185), Ramón Casas. El pintor del modernismo, Mapfre /MNAC, 2001, Madrid. Agradecimientos al Centro de Documentación de la Fundación Picasso de Málaga.

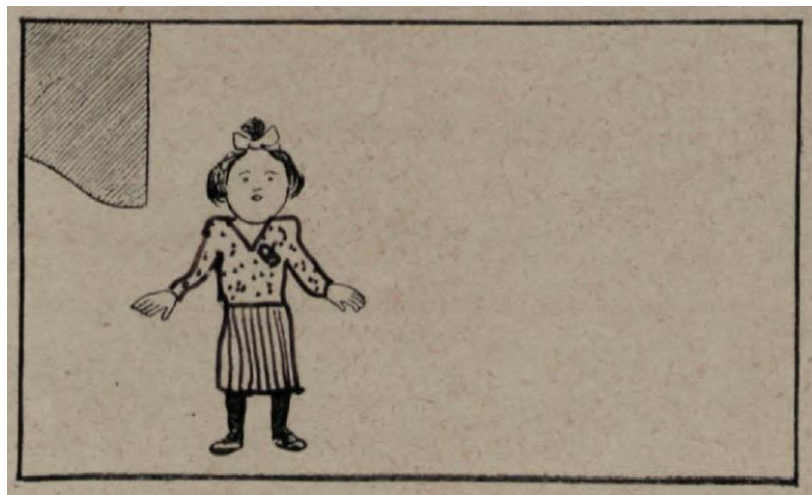

Imagen 7. Xaudaró Echau, J. (1898). Exposición de Bellas Artes. Fotograbado en El Gato Negro, Barcelona, tomo I, $\mathrm{n}^{\mathrm{o}} 19,21 / 5 / 1898, \mathrm{~s} / \mathrm{p}$. Recuperado de https://ddd.uab.cat/pub/gatneg/gatneg_a1898m5d21n19. pdf, p. 13. Agradecimientos al Depòsit Digital de Documents de la Universidad Autónoma de Barcelona. 
La publicación de la versión paródica del cuadro de Picasso dentro de la serie humorística sobre la IV Exposición de Bellas Artes e Industrias Artísticas de Barcelona es una prueba de que Picasso participó en dicha muestra, a pesar de los enigmas que se suscitan, como el de su exclusión del catálogo. No hay que obviar el hecho de que el dato que permite situar a Picasso como expositor en 1898 es una fuente documental primaria, de la prensa gráfica coetánea. Contestar a la pregunta de por qué el episodio no fue referido nunca implica manejar otros argumentos, como el del olvido al no haber obtenido premio alguno o la infravaloración general de los concursos artísticos en el transcurso del tiempo (Gutiérrez Burón, 1986, p. 54), o ambas cosas. Los datos del propio Picasso sobre esos años y los certámenes son dubitativos (Sabartés, 1953, pp. 55-56), y para completar la confusión algunos historiadores hablan de participaciones imposibles inventando certámenes:

En este sentido y aunque la mayoría de los estudiosos de la obra de Picasso así lo afirman, conviene aclarar que Ciencia y Caridad no se expuso en la tierra natal del pintor ni formó parte de la Exposición Regional de 1897 ni tampoco fue premiada en la misma, entre otras cosas porque ese año no se celebró concurso pictórico alguno en la ciudad. (Moreno, 2009, p. 68)

Los adelantos técnicos reproductivos que llevan a la proliferación de las imágenes y el abaratamiento de los costes productivos con la consiguiente democratización del arte es un proceso imparable desde principios del siglo XIX (Ramírez, 1988). La cultura visual de los medios impresos no era en absoluto ajena a Picasso, como a cualquier persona en el mundo del arte. Es el momento histórico en el que las revistas ilustradas de gran formato denominadas ilustraciones, dirigidas a un público culto pero diverso y basadas en un principio en reproducciones xilográficas a contrafibra, van cediendo su lugar en las librerías a revistas de menor formato donde predomina el fotograbado, que intentan llegar a un mayor público, a menor precio y con nuevos intereses (Bozal, 1979, p. 182). Publicar en una revista era consolidarse como artista profesional, moderno, que afronta la nueva realidad y puede mantenerse de su trabajo, necesidad incluso para consagrados como Joaquín Sorolla (Alcaide; Pérez Rojas; Escriche, 2001, p. 18); 1898 es el año en el que Picasso manda un dibujo a la Llibrería Espanyola que será reproducido en Almanach de La Esquella de la Torratxa pera 1899. Conocía la revista El Gato Negro, sin ninguna duda, pues se encuentra una especie de pequeño boceto de portada, con el título El Gato 
Negro, en una de sus hojas de apuntes (Richet, 1988, MPP 415 verso). Cardona, compañero de estudios en la Lonja, ya había colaborado y firmado magníficas portadas para la cabecera, con color incluido (véase Imagen 8). La denominada baja cultura ha sido parte constante y con gran intensidad de la alta cultura desde la segunda mitad del siglo XIX (Robles, 2008, p. 58). Editado el número cuando todavía se encontraba en Madrid, es posible especular también con la posibilidad de que Picasso antes o después pudiera ver su cuadro interpretado. Tampoco es descartable que pudiera conocer al propio Xaudaró, bien conectado con el ambiente pictórico barcelonés desde 1895, y desde 1898 en la redacción artística de Blanco y Negro, junto al malagueño José Blanco Coris, con viajes entre las dos ciudades, como los que hizo Picasso en similares fechas.

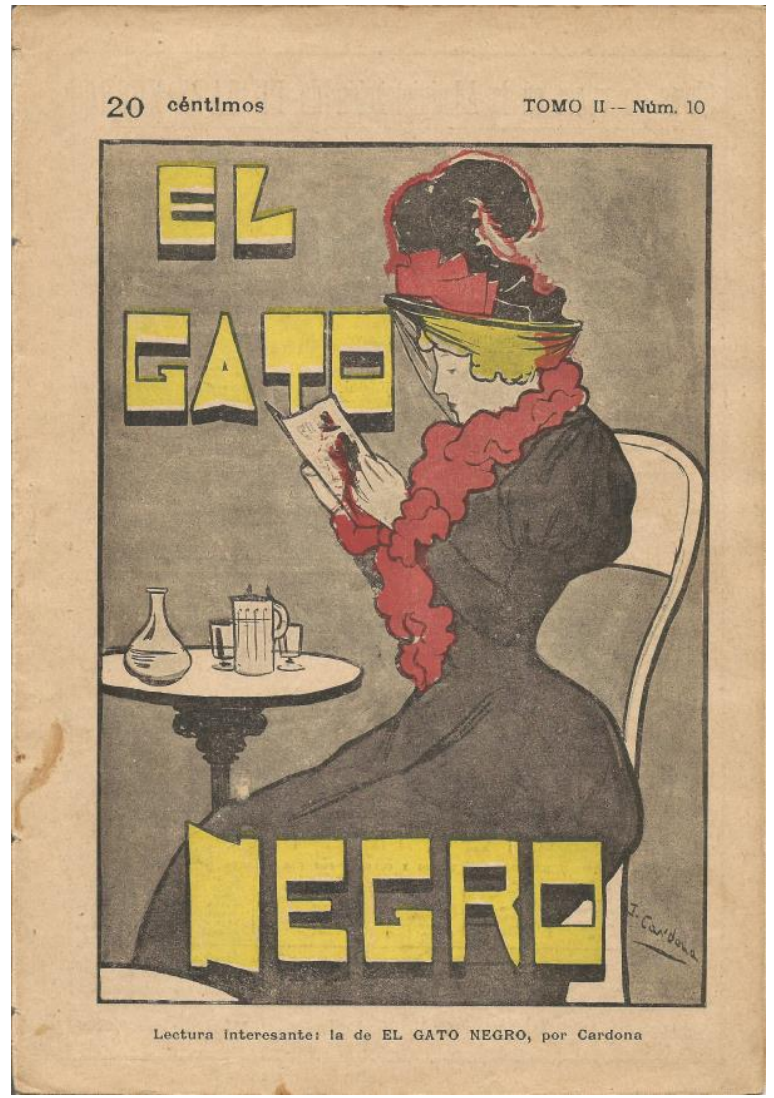

Imagen 8. Cardona Lladós, J. (1898). Fotograbado en El Gato Negro, Barcelona, tomo II, $\mathrm{n}^{\circ} 10$, 3/9/1898, portada. Col. BASL, Málaga. 
A modo de epílogo, Xaudaró volvería a reinterpretar a Picasso con ocasión de la Exposición Nacional de Bellas Artes de Madrid de 1899, donde el artista obtuvo una pequeña recompensa, la mención honorífica al lienzo titulado Un patio de una casa de Aragón, posteriormente denominado Costumbres aragonesas. La revista Blanco y Negro, la más vendida de su género ya en esas fechas y que salía semanalmente al mercado con veinte páginas, dedicaba catorce de ellas completas a la Exposición, dos de las cuales eran viñetas satíricas sobre los cuadros y esculturas de la muestra (Xaudaró, 1899, s. p.). El paradero desconocido del cuadro original y la falta de otro tipo de reproducciones, unido a las escasas obras relacionadas, algo inusual en Picasso, ha dado relevancia a la parodia con enormes repercusiones historiográficas. Ese cuadro premiado es su última recompensa española.

El joven Pablo Ruiz llega a ser conocido como Picasso en otra tierra, pero en sus dibujos tempranos, como se puede observar en su obra catalogada, están patentes las páginas de la cultura popular de su país, democrático universo de viñetas y tipografías (Haro; Soto, 2011, pp. 133134) habitado con anterioridad a la gráfica ciudad de París (Cate, 1997, p. 141).

\section{Referencias}

Alcaide, J. L.; Pérez Rojas, J.; Escriche, M. (2001). Arte y propaganda: carteles de la Universitat de València. Valencia: Universidad. Barrachina, J. et al. (1986). Museu Picasso: Catálogo de pintura y dibujo. Barcelona: Ayuntamiento.

Bozal, V. (1979). La ilustración gráfica del siglo XIX en España. Madrid: Alberto Corazón.

Caparrós Masegosa, M $\mathrm{M}^{\mathrm{a}}$ D. (2014). Historia y crítica de las Exposiciones Nacionales de Bellas Artes (1901-1915). Granada: Universidad.

Carandente, G. (1981). Picasso. Opere dal 1895 al 1971 dalla collezione Marina Picasso. Florencia: Sansoni.

Casado Cimiano, P. (2006). Diccionario biográfico de ilustradores españoles del siglo XIX. Madrid: Ollero y Ramos.

Casellas, R. (1892). “Bellas Artes. Luis Graner”. La Vanguardia, 29/3/1892. Cate, P. D. (1997). "Fumism and Other Aspects of Parisian Modernism in Picasso's Early Drawings". En Picasso. The Early Years 1892-1906. Washington: National Gallery of Art, pp. 133 a 141. 
Clémentson Lope, M. C. (1985). El mundo clásico en José Garnelo y Alda. Córdoba: Diputación.

Doñate, M.; Mendoza, C. (2001). Ramón Casas. El pintor del modernismo. Madrid: Mapfre /MNAC.

Eco, U. (1995). Apocalípticos e integrados. Barcelona: Lumen.

Esain, J. (1992). Picasso y Aragón. Zaragoza: Ibercaja.

Fanés, F. (2012). Un collage antes del collage. Barcelona: Museu Picasso.

García Guatas, M. (2013). "Oficios del pintor en el siglo XIX”. En Actas del Curso Arte del siglo XIX. Zaragoza: Institución Fernando el Católico, pp. 313-359.

García-Herraiz, E. (1997). "Picasso en Horta (1898-1899): misterios de Arcadia”. Archivo Español de Arte, LXX, 277, enero-marzo 1997, pp. 37-55.

Gutiérrez Burón, J. (1986). "Picasso y las exposiciones nacionales: tradición y ruptura”. En V Congrés Espanyol d'Història d'Art. Barcelona: Generalitat, pp. 53-62.

Haro, S.; Soto, I. (2011). “Plásticas de la narración”. En Viñetas en el frente. Barcelona: Museu Picasso, pp. 132-149.

Jardí, E. (1975). Joaquín Mir. Barcelona: Polígrafa.

Mallén, E. (2017). Online Picasso Project. Texas: Sam Houston State University.

Moreno, J. M. (2009). La recuperación progresiva. Málaga: Real Academia de Bellas Artes de San Telmo.

Ocaña, M. T. (2003). "La incidencia de D. José Ruiz Blasco en la formación de un genio". En Picasso Joven. A Coruña: Fundación Pedro Barrié de la Maza.

Ojuel, M. (2013). Les exposicions municipals de belles art i indústries artístiques de Barcelona (1888-1906). Barcelona: Universidad Autónoma.

Ortiz, D. (1898). “Crónica chirigotera”. El Gato Negro, tomo I, n 19, 21/5/1898.

Ossorio y Gallardo, C. (1896). "Actualidades artísticas (salón Parés)”. Barcelona Cómica, $\mathrm{n}^{\circ}$ 6, 8/2/1896.

Palau i Fabre, J. (1980). Picasso vivo: 1881-1907. Infancia y primera juventud de un demiurgo. Barcelona: Polígrafa.

Palomo, F. J. (1985). Historia Social de los pintores del siglo XIX en Málaga. Málaga: edición del autor.

Pardo E.; Ventureira, R. (2014). Picasso azul y blanco. A Coruña: el nacimiento de un pintor. A Coruña: Hércules de ediciones. 
Pazos, M. A. (1981). "En el umbral de Picasso: José Ruiz Blasco". En Picasso y Málaga. Madrid: Ministerio de Cultura, pp. 5-35. Texto reimpreso en VVAA (2004). José Ruiz Blasco (1838-1913). Málaga: Fundación Picasso, pp. 53-76.

Ramírez, J. A. (1988). Medios de masas e historia del arte. Madrid: Cátedra. Richardson, J. (1995). Picasso. Una biografía. Vol. I: 1881-1906. Madrid: Alianza.

Richet, M. (1988). Musée Picasso Paris. Dibujos, acuarelas, gouaches, pasteles. Vol. II. Barcelona: Polígrafa.

Robles Tardío, R. (2008). Pintura de humo. Madrid: Siruela.

Rojas, C. (1981). La Barcelona de Picasso. Barcelona: Plaza \& Janés.

Rovira, P. (1898). "Exposición del Círculo de Bellas Artes". La

Correspondencia de España, no 14.713, 16/5/1898, pp. 3-4.

Sabartés, J. (1953). Picasso. Retratos y recuerdos, Madrid: Afrodisio Aguado.

Sánchez Vigil, J. M. (2008). Revistas ilustradas en España. Del

Romanticismo a la guerra civil. Gijón: Trea.

Sanmartín, J. F. (1901). "Perfiles cómicos. Joaquín Xaudaró”. Iris, n 132, $16 / 11 / 1901$.

Staller, N. (2001). A sum of destructions. Picasso's Cultures and the

Creation of Cubism. New Haven /Londres: Yale University Press.

Sureda, J.; Guasch, A. Ma (1993). La trama de lo moderno. Madrid: Akal. Vallès, E. (2010). Picasso versus Rusiñol. Barcelona: Museu Picasso.

Xaudaró, J. (1899). "La exposición cómica". Blanco y Negro, n’ 419, $13 / 5 / 1899, \mathrm{~s} / \mathrm{p}$.

Zervos, C. (1969). Pablo Picasso: Supplément aux années 1892-1902. Vol. 21. París: Cahiers d'Art.

\section{Referencias Documentales}

Acto de barnizado y Terminación de la Instalación de obras que figurarán en la Exposición, el día 22 de los corrientes, invitación Palacio de Bellas Artes, 1898 (abril), Arxiu Históric de la Ciutat de Barcelona, Barcelona, AHCB4-326/C14.02, PBA-10.

Catálogo ilustrado. IV Exposición de Bellas Artes e Industrias Artísticas 1898, Henrich y Cía en comandita, Barcelona, 1898.

La Dinastía, $\mathrm{n}^{\circ}$ 6550, 26/5/1898.

La Esquella de la Torratxa, año 20, no 1007, 29/4/1898, p. 283.

La Ilustración Ibérica, nº 802, 14/5/1898, p. 311. 
Reglamento Cuarta Exposición de Bellas Artes e Industrias Artísticas, Ayuntamiento, Barcelona, 1898.

La Vanguardia, 29/1/1898, p. 3.

La Vanguardia, 26/2/1898, p. 2.

La Vanguardia, 22/5/1898, p. 4.

La Vanguardia, 11/7/1898, p. 1.

Inocente Soto: Doctor en Bellas Artes. Profesor de la Facultad de Bellas Artes de la Universidad de Málaga.

Email address: inocentesoto@uma.es

Web: https://uma.academia.edu/InocenteSoto

Contact Address: Facultad de Bellas Artes. Universidad de Málaga. Plaza de El Ejido n¹. Campus de El Ejido 29071. Málaga 